\title{
A vulnerabilidade social aos perigos naturais e tecnológicos em Portugal
}

Social Vulnerability to Natural and Technological Hazards in Portugal

La vulnérabilité sociale face aux risques naturels et technologiques au Portugal

José Manuel Mendes, Alexandre Oliveira Tavares, Lúcio Cunha e Susana Freiria

\section{OpenEdition}

\section{Journals}

Edição electrónica

URL: http://journals.openedition.org/rccs/90

DOI: $10.4000 /$ rccs. 90

ISSN: 2182-7435

\section{Editora}

Centro de Estudos Sociais da Universidade de Coimbra

Edição impressa

Data de publição: 1 Junho 2011

Paginação: 95-128

ISSN: 0254-1106

Refêrencia eletrónica

José Manuel Mendes, Alexandre Oliveira Tavares, Lúcio Cunha e Susana Freiria, «A vulnerabilidade social aos perigos naturais e tecnológicos em Portugal ", Revista Crítica de Ciências Sociais [Online] 93 | 2011, colocado online no dia 22 maio 2012, criado a 30 abril 2019. URL : http:// journals.openedition.org/rccs/90; DOI : 10.4000/rccs.90 


\section{JOSÉ MANUEL MENDES, ALEXANDRE OLIVEIRA TAVARES, LÚCIO CUNHA, SUSANA FREIRIA}

\section{A vulnerabilidade social aos perigos naturais e tecnológicos em Portugal}

Neste artigo apresenta-se um novo modelo de análise da vulnerabilidade social aos perigos naturais e tecnológicos. O índice utilizado nesta análise permite a estruturação da avaliação da vulnerabilidade em duas dimensões: as vulnerabilidades das populações e comunidades (criticidade) e a vulnerabilidade territorial (capacidade de suporte), os quais reflectem a exposição ou a vulnerabilidade biofísica, a resiliência social e a capacidade de suporte infraestrutural. Este novo índice de vulnerabilidade social é aplicado ao sistema territorial de Portugal continental, tendo por base a escala municipal e submunicipal, apreendendo a resiliência social dos indivíduos, dos grupos e das comunidades face a acontecimentos extremos.

Os resultados obtidos evidenciam o papel crucial da escala na análise dos processos relacionados com a vulnerabilidade social. Propõe-se que a cartografia das áreas e dos grupos mais vulneráveis, bem como a identificação dos factores desencadeantes, podem constituir um contributo relevante para os programas de ordenamento e de planeamento destinados a mitigar os riscos e as vulnerabilidades do território.

Palavras-chave: desastres naturais; escalas de avaliação; factores de risco; resiliência; riscos naturais e tecnológicos; território; vulnerabilidade social.

\section{Introdução}

O presente artigo propõe uma abordagem, a múltiplos níveis, da vulnerabilidade social relacionada com os perigos naturais e tecnológicos em Portugal continental, partindo de uma perspectiva multidisciplinar.

Historicamente, o conceito de vulnerabilidade social emergiu como uma crítica explícita aos paradigmas dominantes e convencionais de análise dos desastres, cabendo a Hewitt (1983) a formulação mais cabal dessa crítica. Expressando o mesmo sentido, Bolin (2006) salienta a importância de examinar os processos económicos e espaciais de marginalização que constrangem certos grupos sociais a ocuparem áreas e zonas marcadas por perigos naturais e tecnológicos. 
A vulnerabilidade aos perigos, como referem Wisner et al. (2004), é um processo constituído por componentes que envolvem causas profundas (factores históricos, políticos, económicos, ambientais e demográficos que produzem desigualdades), pressões dinâmicas (processos sociais específicos como, por exemplo, uma rápida urbanização, conflitos sociais, etc.) e condições de vida pouco seguras (exposição desigual ao risco). Assim, o conceito de vulnerabilidade social está associado ao grau de exposição aos perigos naturais e tecnológicos e aos acontecimentos extremos, dependendo estreitamente da capacidade de resistência e de resiliência dos indivíduos e das comunidades mais afectadas. Autores como Maskrey (1989) ou Oliver-Smith (2004) defendem a integração dos factores biofísicos e socioculturais na análise da vulnerabilidade social, o que implica uma perspectiva mais abrangente, em que a vulnerabilidade se afirma como um conceito de ecologia política e incorpora a multidimensionalidade dos perigos e dos desastres. Esta visão ecológica e política, nomeadamente expressa por Perrow $(2007 ; 2006)$, suscita uma reflexão quanto aos factores estruturais da vulnerabilidade social e à sua integração explícita nos planos de ordenamento do território. Partindo da teoria dos acidentes normais e da constatação que as organizações falham de forma permanente e constante, Perrow (2006) defende a necessidade premente de redução das vulnerabilidades, contra a simples prevenção, mitigação ou limitação dos danos.

Estas abordagens compósitas da construção da vulnerabilidade social aos perigos sugerem que a análise deve conter a totalidade das inter-relações culturais, societais e naturais de uma dada situação, o que implica a ideia de que os desastres são sempre sociais e não o produto de condições naturais específicas e que é determinante o papel das forças, organizações e crenças que estão na base da produção do ambiente que origina e facilita os desastres.

Segundo Kuhlicke et al. (2011), a vulnerabilidade é um produto de determinados contextos espaciais, socioeconómicos, demográficos, culturais e institucionais, pelo que a sua abordagem é sensível às condições locais e à dimensão temporal. Os resultados da análise são colocados num contexto mais amplo, não só no que toca à vulnerabilidade, mas também à resistência das populações e aos parâmetros da investigação sobre o risco. A noção de vulnerabilidade como forma de análise da adaptação e capacidade adaptativa dos residentes e comunidades é igualmente expressa por Hufschmidt (2011), acentuando este que a compreensão da vulnerabilidade e da resiliência exige uma atenção explícita às interdependências escalares, quer espaciais quer temporais. 
Conforme referem Bohle et al. (1994) e Schmidtlein et al. (2008), os antecedentes dos actuais modelos de avaliação da vulnerabilidade social baseavam-se em indicadores sociais e de qualidade de vida e, ulteriormente, em indicadores de desenvolvimento humano, os quais apresentam como maior constrangimento a sua não representação a escalas subnacionais. Inúmeros autores (Cutter, 2003; Davis, 2004) e organizações (ISDR, 2004; IFRCRCS, 2010) têm apresentado metodologias de análise da vulnerabilidade social aos perigos, permitindo ampliar e validar novos referenciais e a selecção de diversos indicadores.

As diferentes acepções do termo e as diversas explanações metodológicas da avaliação da vulnerabilidade social aos perigos naturais e tecnológicos suscitam a necessidade de aprofundar a avaliação da resiliência social dos indivíduos, dos grupos e das comunidades, dado que, como salientam Fraser et al. (2003), os indicadores de vulnerabilidade nacionais camuflam frequentemente a variabilidade que existe nas unidades de análise e usam limites sociais e artificiais para medir processos que na realidade ocorrem dentro de limites ambientais.

Nesse sentido, procura-se evidenciar no sistema territorial de Portugal continental, tendo por base a escala local (município e freguesia), uma metodologia de avaliação da vulnerabilidade social aos perigos em que, a partir de índices, se avalie a capacidade de suporte e a criticidade locais, as quais configuram a resiliência social dos indivíduos, dos grupos e das comunidades.

O principal objectivo do presente trabalho é estabelecer uma análise multidisciplinar da vulnerabilidade social associada aos perigos naturais e tecnológicos, a partir de um conhecimento aprofundado dos territórios, ultrapassando o constrangimento das escalas subnacionais de análise.

Procede-se à proposta de um novo índice de vulnerabilidade social, que comporta duas dimensões distintas, a criticidade e a capacidade de suporte, incorporando-se os efeitos de escala na mensuração das dimensões territoriais associadas à vulnerabilidade. São, assim, calculados e representados cartograficamente os índices de vulnerabilidade social para a totalidade dos municípios portugueses e para uma subamostra de sete municípios da região centro, os quais funcionam como subescala de análise e de validação do modelo proposto.

Com esta avaliação pretende-se ainda testar a relação entre a escala e as variáveis determinantes na avaliação da vulnerabilidade social, suscitando a reflexão sobre a influência dos dados de base na construção dos índices e a diferente reprodutibilidade a escalas municipais e submunicipais.

Procura-se, assim, construir índices de vulnerabilidade para Portugal continental que representem as inter-relações culturais, societais e naturais, 
de forma a avaliar a resiliência e resistência dos indivíduos e comunidades, quando expostas a processos ou acontecimentos perigosos, possibilitando a fundamentação de acções e instrumentos de planeamento e de protecção civil.

\section{Contextualização e perspectiva teórica sobre a vulnerabilidade social}

A nível mundial tem-se assistido ao aumento crescente do número de desastres registados com maior impacto nas vidas das populações e nos sistemas socioeconómicos (ISDR, 2011; WEF, 2010; Guha-Sapir et al., 2011). Segundo os dados do The International Disaster Database, do Centre for Research on the Epidemiology of Disasters, entre 1900 e 2009 registou-se um decréscimo em termos de vítimas mortais, mas um aumento do número de pessoas afectadas e dos prejuízos materiais devido à ocorrência de desastres (Rodriguez et al., 2009). Durante várias décadas a análise dos riscos naturais centrou-se nos processos geofísicos, negligenciando aspectos como as estratégias individuais e colectivas para enfrentar as crises, a vulnerabilidade das pessoas e dos grupos e a capacidade de resiliência das comunidades.

O conceito de vulnerabilidade social tem sido trabalhado por diferentes autores, com propostas de definições próximas, mas com acentuação diferenciada dos factores relevantes. Assim, nos documentos da ISDR (2011; 2005) o termo refere-se à propensão da população exposta para os perigos ou dos recursos económicos para as perdas, na estreita dependência de características físicas, sociais, políticas, económicas, culturais e institucionais dos territórios afectados. Para Dwyer et al. (2004) e a EC-DGE (2008), a vulnerabilidade social define a capacidade de um elemento recuperar do impacto de um desastre natural. $\mathrm{Na}$ acepção de Wisner et al. (2004) e de Hufschimdt et al. (2005), a vulnerabilidade social representa o nível de resiliência e de resistência dos indivíduos e comunidades quando expostos a processos ou acontecimentos perigosos.

Autores como Prescott-Allen (2001) e Eakin e Luers (2006) salientam, na avaliação da vulnerabilidade social, a interacção existente entre o ser humano e o ambiente, ou, como suscita (Phillips et al., 2009), que a definição de vulnerabilidade social se baseia no nível de propensão individual e colectiva para se ser afectado pelos riscos e na capacidade de resposta a um acontecimento perigoso. Neste âmbito, procura-se metodologicamente desagregar as dimensões relacionadas com as características individuais e com as características estruturais.

A capacidade de avaliar a vulnerabilidade social é progressivamente entendida como um factor chave para um efectivo processo de redução do risco e a promoção de uma cultura de resiliência (Birkmann, 2006; Langridge et al., 2006). Independentemente das perspectivas diferentes 
adoptadas pelos vários autores, parece haver consenso quanto ao facto de a vulnerabilidade social não ser uma simples consequência da exposição aos perigos, mas sim o resultado de condições de desigualdade social que precedem a ocorrência desses processos e que podem estar relacionados com factores como a pobreza, a idade, o género ou a classe social (Bankoff, 2004; Bolin, 2006; Cutter, 2003 e 2006; Cutter et al., 2006; Dwyer, 2004; Fekete, 2009; Kuhlicke et al., 2011; Langridge et al., 2006).

Assume-se, assim, que as componentes da vulnerabilidade social variam em função de características das comunidades que, à partida, não estão directamente relacionadas com a perigosidade, que constitui o lado biofísico dos riscos, mas sim com o grau de desenvolvimento económico, o acesso a recursos, os modos de vida e os meios de subsistência das pessoas e dos grupos afectados. As populações vulneráveis são aquelas que se encontram em risco não simplesmente porque estão expostas aos perigos, mas como resultado da marginalidade em que vivem, fazendo das suas vidas uma "emergência permanente" (Cutter, 2006 e 2010).

$\mathrm{Na}$ última década foram levados a cabo vários trabalhos quantitativos e qualitativos no âmbito da avaliação da vulnerabilidade social, tais como Belmonte et al. (2008), Fekete (2009), Glatron e Bech (2008), de Graaf et al. (2007), Iglesias et al. (2009), Keskitalo (2008), Kropp et al. (2006), Peduzzi et al. (2009), Roselló et al. (2009), Tapsell et al. (2010). Destes, saliente-se os trabalhos de Fekete (2009), que se centrou na avaliação da vulnerabilidade da população a cheias nas bacias do Reno, Elba e Danúbio, ou de Graaf et al. (2007) e Belmonte et al. (2008), analisando a vulnerabilidade da população a acontecimentos climáticos extremos. Estes autores desenvolvem a avaliação da vulnerabilidade social em função de uma ou mais perigosidades, na maioria dos casos relacionadas com acontecimentos climáticos extremos.

Além disso, são vários os trabalhos que se concentram numa determinada área geográfica. Pode ser apontado, como exemplo, o Projecto Espon 1.3.1 Hazards (Kumpulainen, 2006), cuja área de estudo abrangeu os 27 Estados-Membros da União Europeia e no qual se procurava identificar a vulnerabilidade da população aos impactos das mudanças climáticas em perigosidades como as ondas de calor.

De acordo com Tapsell et al. (2010) é relevante ter em conta cinco parâmetros na selecção de dados quantitativos para a análise da vulnerabilidade social: a disponibilidade, a qualidade, a validação e a avaliação dos dados e o peso dos indicadores a utilizar na operacionalização da vulnerabilidade social. No que concerne à disponibilidade dos dados, é de assinalar que à medida que a escala de análise se vai tornando mais pormenorizada 
o número e a qualidade dos dados vão diminuindo. Segundo Adger et al. (2004), na selecção de indicadores da vulnerabilidade social é possível adoptar dois tipos de metodologias, uma baseada na compreensão teórica das relações e outra baseada nas relações estatísticas. A existência de uma boa matriz conceptual na selecção das variáveis assume-se, como tal, relevante na definição de índices de avaliação da vulnerabilidade social, evitando a expansão de variáveis e permitindo a compreensão teórica das relações entre variáveis, dado que, como sugere Fekete (2009), a vulnerabilidade social é de difícil operacionalização, enredada em vários aspectos humanos e dependente de contingências ligadas a diferentes níveis societais.

Em Portugal são poucos os trabalhos que incidem sobre os índices de vulnerabilidade social, sendo de assinalar a proposta teórica de Ribeiro (1995) e o estudo empírico do mesmo autor (Ribeiro, 2006), no qual são propostas metodologias estatísticas de avaliação, sendo o sistema territorial representado por uma freguesia de Lisboa na hipótese de ser afectada por um sismo. É de referir também o trabalho de Mendes (2007 e 2009), que desenvolveu um índice de vulnerabilidade social para a região centro de Portugal num quadro de exposição a vários perigos, ou o trabalho de Mendes et al. (2010), precursor deste artigo.

Apesar desta escassez de trabalhos académicos sobre a vulnerabilidade social, é possível identificar no contexto português vários acontecimentos recentes, como as cheias do Inverno de 2000/2001, os incêndios florestais de 2003 e as ondas de calor de 2003 e 2006, em que as comunidades evidenciaram elevados níveis de vulnerabilidade social, ao nível das dimensões relacionadas com as características individuais e com as características estruturais dos territórios afectados.

No âmbito do ordenamento e planeamento nacional e regional em Portugal, os planos e instrumentos existentes não incorporam a análise da vulnerabilidade social ou os indicadores associados à mesma como determinantes no desenho e implementação de medidas de prevenção. O mesmo acontece na articulação entre as actividades socioeconómicas e as políticas e as infraestruturas de proteç̧ão civil (Tavares et al., 2010).

$\mathrm{Na}$ nossa perspectiva, a cartografia das áreas e dos grupos mais vulneráveis, bem como a identificação dos factores desencadeantes, podem contribuir para mudar o enquadramento legal da protecção civil e das políticas de governação em Portugal (Mendes e Tavares, 2009), ou ainda, segundo o Guia para Caracterização do Risco no âmbito da elaboração de Planos de Emergência de Proteç̧ão Civil (ANPC, 2009), contribuir para a adopção de projectos ou de programas integrados destinados a mitigar os riscos e as vulnerabilidades do território. 


\section{Metodologia para avaliação da vulnerabilidade social}

No presente trabalho preconiza-se uma abordagem integrada da vulnerabilidade social, procedendo à combinação dos factores "internos" do sistema vulnerável com a exposição às perigosidades externas (Füssel, 2007), sem dar primazia a nenhuma perigosidade em particular. Além disso, a metodologia proposta neste artigo pretende demonstrar a importância de cartografar a vulnerabilidade social a diferentes escalas, apresentando uma avaliação ao nível dos municípios de Portugal continental e ao nível submunicipal, com base numa amostra de sete municípios, seleccionados pelos contrastes das características biofísicas e socioeconómicas e pela sua distribuição espacial: Almeida, Coimbra, Fundão, Marinha Grande, Nelas, Ovar e Proença-a-Nova.

Adopta-se na análise o propósito de avaliar a propensão individual e colectiva para a exposição ao risco, bem como a capacidade de resposta a um acontecimento perigoso, baseada nas características dos indivíduos, grupos e comunidades e nas características estruturais dos territórios. Assim, a avaliação apresentada para a vulnerabilidade social assenta num processo de duas etapas, com definição de índices para a criticidade e a capacidade de suporte do sistema territorial.

Neste contexto, o conceito de criticidade é entendido como o conjunto de características e comportamentos dos indivíduos que podem contribuir para a ruptura do sistema e dos recursos das comunidades que lhes permitem responder ou lidar com cenários catastróficos. No entanto, o sistema territorial possui igualmente um conjunto de recursos que permitem enfrentar uma eventual crise. Neste sentido, a par da criticidade, considera-se necessário contemplar aquilo que foi denominado de capacidade de suporte, ou seja, o conjunto de infraestruturas territoriais que permite à comunidade reagir em caso de desastre ou catástrofe. O conceito de vulnerabilidade social é, assim, definido como o nível de resiliência ou resistência dos indivíduos e comunidades quando expostos a processos ou acontecimentos danosos e resulta da conjugação da criticidade e da capacidade de suporte. ${ }^{1}$

Conforme enunciado anteriormente, estabelece-se uma representação da vulnerabilidade social à escala subnacional (ao nível dos municípios) e submunicipal (ao nível das freguesias), o que implica a articulação de diferentes escalas locais.

\footnotetext{
${ }^{1}$ Para uma excelente análise das diferentes propostas teóricas sobre o conceito de resiliência e a sua relação com o conceito de vulnerabilidade, ver Manyena (2006). Para uma análise da aplicação do modelo de Susan Cutter na perspectiva da resiliência social, ver Cutter et al. (2008).
} 
Com base na disponibilidade e qualidade dos dados quantitativos e na selecção e validação do peso dos factores relevantes na modelização realizada, propõe-se um algoritmo que permite a avaliação da vulnerabilidade à escala municipal e submunicipal. As fontes utilizadas na avaliação da vulnerabilidade social incluem exclusivamente bases de dados de organismos institucionais, como o Instituto Nacional de Estatística e o Instituto Nacional da Água, entre outros.

As variáveis encontravam-se organizadas em dez categorias consideradas relevantes: alojamentos, apoio social, demografia, economia, edifícios, educação, justiça, protecção civil, saneamento básico e saúde, resultando os índices de avaliação da vulnerabilidade social da conjugação do conjunto de variáveis, apoiada posteriormente na aplicação da análise factorial.

A vulnerabilidade social é, assim, avaliada através da análise factorial, metodologia preconizada por autores como Cutter et al. (2003), Mendes (2007 e 2009) e Schmidtlein et al. (2008), com algumas adaptações à realidade dos estudos de caso, assim como aos objectivos do presente trabalho.

A análise factorial de componentes principais (ACP) apresenta-se como uma metodologia útil, que permite eliminar do universo em análise as variáveis redundantes, proceder à sua normalização e agrupá-las em diferentes factores. Trata-se de uma metodologia cuja elaboração é desenvolvida com base nos seguintes passos:

(i) Normalização das variáveis a partir dos denominados z-scores, cuja média é zero e o respectivo desvio-padrão é 1.

(ii) Execução da análise factorial no SPSS (versão 17).

(iii) Avaliação da matriz de correlação dos dados, no sentido de eliminar do universo em análise os dados redundantes (análise da multicolineariedade).

(iv) Após a exclusão dos dados redundantes, executa-se novamente a análise factorial até se atingir determinados parâmetros considerados necessários para que a amostra seja considerada válida. Pode-se apontar como exemplo desses parâmetros uma taxa de variância superior a $60 \%$, um valor de KMO (Kaiser-Meyer-Olkin) e de níveis de comunalidades superiores a 0.6.

(v) Interpretação e escalamento dos factores resultantes, no modo como estes influenciam a vulnerabilidade social. Uma vez que os valores nem sempre apresentam a orientação desejada, torna-se necessário escalar os índices parcelares no sentido de que quanto mais elevado o resultado final da equação mais elevada seja a vulnerabilidade social de determinado espaço. Neste sentido, no caso de os scores factoriais de variáveis que contribuem 
para diminuir a vulnerabilidade apresentarem uma orientação positiva, será necessário a sua multiplicação por -1 .

(vi) Combinação dos scores factoriais resultantes da análise num único valor, o que significa que cada unidade geográfica vai ter um determinado valor, em termos de criticidade ou capacidade de suporte.

(vii) Exportação dos dados do SPSS para o ArcGIS 9.2 (ESRIÒ), a fim de projectar os resultados na sua componente espacial. A união entre a tabela exportada do SPSS e a tabela do ArcGIS é feita através do código de cada unidade geográfica. No presente caso foram usados os códigos da BGRI (Base Geográfica de Referenciação da Informação atribuídos pelo INE).

(viii) Classificação dos resultados finais da equação de avaliação da vulnerabilidade social com base nos critérios usados por Cutter et al. (2003), conforme se passa a expor: Muito Baixo: menor que -1 D.P.'; Baixo: entre -1 e - 0.5 D.P.; Médio: entre - 0.5 e 0.5 D.P.; Elevado: entre 0.5 e 1 D.P.; Muito Elevado: maior que 1 D.P.

Os índices obtidos no cálculo da criticidade e da capacidade de suporte foram ajustados de forma a que elevados valores de criticidade e baixos níveis de capacidade de suporte signifiquem um elevado nível de vulnerabilidade social, o que permite associar o resultado num único índice. Assim, os resultados finais da criticidade e da capacidade de suporte foram submetidos a uma transformação linear quadrática, para que a amplitude de ambos os índices variasse entre 0 e 1 .

O índice final da vulnerabilidade social surge como o produto da multiplicação dos valores da criticidade pelos valores da capacidade de suporte, de acordo com a proposta de Cox (2009), dado que, segundo este autor, um algoritmo multiplicativo e não-compensatório permite a modelização e a análise das interdependências entre as variáveis retidas no modelo.

A última fase de análise consistiu na hierarquização das classes segundo o desvio-padrão, tal como foi proposto por Cutter et al. (2003), dado que é importante assinalar, no que concerne à hierarquização dos dados, os que devem ser analisados em termos comparativos com as restantes zonas incluídas no modelo.

Para uma melhor explicitação da metodologia apresentam-se seguidamente as variáveis utilizadas na avaliação estatística convencional para obtenção dos índices de criticidade e de capacidade de suporte. A análise permite reduzir de forma substancial as variáveis explicativas do modelo, evitando redundâncias e incrementando o grau de comunalidade.

${ }^{2}$ D.P.: Desvio-Padrão em relação à média. 


\subsection{Variáveis de análise da criticidade e da capacidade de suporte à escala municipal}

Para a avaliação dos índices de criticidade para a totalidade dos municípios de Portugal continental utilizaram-se 90 variáveis, as quais foram reduzidas a 56 após uma análise da multicolinearidade a partir das correlações bivariadas entre as mesmas. A aplicação da análise factorial permitiu seleccionar 22 variáveis explicativas (Tabela 1 ).

TABELA 1 - Número de variáveis na avaliação da criticidade à escala municipal

\begin{tabular}{|l|c|c|c|}
\hline \multirow{2}{*}{\multicolumn{1}{c|}{ Grupos }} & \multicolumn{3}{c|}{ Variáveis } \\
\cline { 2 - 4 } & Iniciais & Modelo & Explicativas \\
\hline Apoio social & 18 & 16 & 2 \\
\hline Condição dos edifícios & 10 & 9 & 3 \\
\hline Demografia & 16 & 7 & 2 \\
\hline Economia & 20 & 13 & 9 \\
\hline Educação & 9 & 3 & 2 \\
\hline Habitação & 11 & 8 & 4 \\
\hline Justiça & 5 & 0 & 0 \\
\hline Saúde & 1 & 1 & 0 \\
\hline Total & 90 & 56 & 22 \\
\hline
\end{tabular}

Com base em 22 variáveis explicativas foram retidos 6 factores para análise. Estes factores explicam $76 \%$ da variância entre todos os municípios de Portugal, com um KMO na ordem dos 0.756 e todas as comunalidades acima de 0.6.

$\mathrm{Na}$ primeira fase da avaliação da capacidade de suporte foram tidas em conta 145 variáveis. A análise factorial permitiu verificar que das 61 variáveis incluídas no modelo, 10 eram suficientes para manter a robustez estatística do mesmo (Tabela 2). Estas variáveis estavam relacionadas com as condições económicas dos municípios, as condições de habitação, a disponibilidade de recursos no âmbito da protecção civil e dos serviços de saúde ou relacionados.

No caso da capacidade de suporte foram retidos 4 factores. Estes factores explicam $71 \%$ da variância entre todos os municípios de Portugal, com um KMO na ordem dos 0.7 , e todas as comunalidades acima de 0.6. 
TABELA 2 - Número de variáveis na avaliação municipal da capacidade de suporte

\begin{tabular}{|l|c|c|c|}
\hline \multirow{2}{*}{\multicolumn{2}{c|}{ Grupos }} & \multicolumn{3}{c|}{ Variáveis } \\
\cline { 2 - 4 } & Iniciais & Modelo & Explicativas \\
\hline Economia & 86 & 27 & 4 \\
\hline Edifícios & 11 & 9 & 0 \\
\hline Habitação & 11 & 8 & 1 \\
\hline Protecção Civil & 27 & 7 & 2 \\
\hline Saúde & 10 & 10 & 3 \\
\hline Total & 145 & 61 & 10 \\
\hline
\end{tabular}

\subsection{A criticidade à escala municipal}

$\mathrm{Na}$ avaliação da criticidade à escala municipal foram retidos seis factores, com uma taxa de variância de $76 \%$, que influenciam o resultado final da equação de avaliação da criticidade: o factor 1 representa a estrutura demográfica dos municípios; o factor 2 o poder económico; o factor 3 as condições de habitabilidade; o factor 4 a estrutura socioprofissional; o factor 5 o peso dos beneficiários do Rendimento Mínimo Garantido; e o factor 6 o dinamismo económico dos municípios. Esta selecção de factores pode ser interpretada a partir da Tabela 3, passando-se a descrever com mais detalhe cada factor.

\section{Factor 1 - Estrutura demográfica}

O factor 1 explica 29\% da variância do modelo. Neste factor, a variável dominante é a percentagem de população empregada que se enquadra no grupo socioprofissional 6 da Classificação Nacional de Profissões (CNP) - agricultores e trabalhadores qualificados da agricultura e pesca - que apresenta uma carga negativa, tal como variáveis como a percentagem de indivíduos residentes com idade superior a 65 anos. Com excepção da percentagem de alojamentos familiares clássicos de residência habitual arrendados ou subarrendados, as restantes variáveis do factor encontram-se, ainda que alguns deles de forma indirecta, relacionados com a estrutura demográfica.

Refira-se que os grupos mais vulneráveis a acontecimentos extremos são os adultos com mais de 65 anos e as crianças com menos de 5 anos. Em caso de desastre, estas últimas não possuem o mesmo nível de independência ou disponibilidade de recursos que os adultos (Mitchell et al., 2008). Um primeiro passo na redução da vulnerabilidade das crianças e dos mais idosos envolve o reconhecimento de que estes grupos possuem poucos recursos e capacidade limitada para se prepararem para o desastre. Além disso, enfrentam maiores dificuldades no processo de recuperação (Phillips et al., 2009). 
106 | José Manuel Mendes, Alexandre Oliveira Tavares, Lúcio Cunha, Susana Freiria

TABELA 3 - Avaliação da criticidade à escala municipal - Matriz rodada de componentes

\begin{tabular}{|c|c|c|c|c|c|c|}
\hline Variáveis & 1 & 2 & 3 & 4 & 5 & 6 \\
\hline População empregada - CNP 6 (\%) & -0.862 & -0.120 & 0.005 & 0.121 & 0.133 & -0.178 \\
\hline $\begin{array}{l}\text { Valor médio mensal das prestações por } \\
\text { invalidez }\end{array}$ & 0.740 & 0.150 & -0.072 & 0.163 & -0.310 & -0.123 \\
\hline $\begin{array}{l}\text { Alunos/estabelecimento de educação pré- } \\
\text {-escolar }\end{array}$ & 0.715 & 0.226 & -0.249 & 0.268 & -0.028 & 0.166 \\
\hline $\begin{array}{l}\text { Alojamentos familiares clássicos de resi- } \\
\text { dência habitual arrendados ou subarren- } \\
\text { dados }(\%)\end{array}$ & 0.679 & 0.513 & 0.055 & 0.045 & 0.102 & -0.083 \\
\hline $\begin{array}{l}\text { População residente - com idade superior } \\
\text { a } 65 \text { anos (\%) }\end{array}$ & -0.678 & -0.123 & 0.475 & 0.242 & -0.337 & 0.103 \\
\hline Alojame & -0.661 & -0.213 & -0.028 & 0.408 & 0.007 & 0.276 \\
\hline $\begin{array}{l}\text { População residente com idade inferior a } \\
5 \text { anos }(\%)\end{array}$ & 0.628 & -0.052 & -0.420 & -0.376 & 0.412 & -0.008 \\
\hline $\begin{array}{l}\text { Proporção de alunos por estabelecimento } \\
\text { de ensino secundário }\end{array}$ & 0.535 & 0.169 & -0.518 & -0.077 & 0.156 & -0.049 \\
\hline $\begin{array}{l}\text { Depósitos de clientes (milhares de } € \text { ) } \\
\text { em estabelecimentos de intermediação } \\
{\text { bancária }{ }^{3} / \text { hab }}\end{array}$ & -0.141 & 0.837 & -0.073 & 0.029 & -0.041 & 0.308 \\
\hline Percentagem de poder de compra/Portugal & 0.260 & 0.827 & -0.065 & -0.001 & 0.027 & -0.003 \\
\hline População empregada - CNP 2 (\%) & 0.292 & 0.709 & -0.106 & 0.319 & -0.056 & -0.060 \\
\hline $\begin{array}{l}\text { Alojamentos Familiares Clássicos de Resi- } \\
\text { dência Habitual - Contrato de renda social } \\
\text { ou apoiada (\%) }\end{array}$ & 0.362 & 0.703 & 0.149 & 0.140 & 0.183 & -0.011 \\
\hline Edifícios c & -0.264 & -0.563 & 0.040 & -0.435 & 0.099 & 0.151 \\
\hline Índice de envelhecimento dos edifícios & -0.116 & 0.421 & 0.775 & 0.043 & 0.005 & 0.181 \\
\hline Edifícios construídos antes de 1919 (\%) & -0.324 & -0.230 & 0.760 & -0.083 & 0.099 & 0.173 \\
\hline Alojamentos com renda inferior a $100 €(\%)$ & 0.361 & 0.077 & 0. & 0.210 & 0.169 & -0.208 \\
\hline População empregada - CNP 1 (\%) & 0.174 & 0.413 & -0.603 & -0.006 & -0.140 & 0.270 \\
\hline População empregada - CNP 5 (\%) & 0.167 & 0.002 & 0.024 & 0.834 & -0.052 & 0.293 \\
\hline População empregada - CNP 8 (\%) & 0.274 & -0.222 & -0.004 & -0.762 & -0.329 & -0.023 \\
\hline População empregada - CNP 7 (\%) & 0.144 & -0.297 & -0.220 & -0.752 & 0.211 & 0.113 \\
\hline $\begin{array}{l}\text { Beneficiários do Rendimento Social de } \\
\text { Inserção (\%) }\end{array}$ & -0.075 & 0.022 & 0.150 & 0.014 & 0.887 & -0.007 \\
\hline $\begin{array}{l}\text { Actos notariais celebrados por escritura - } \\
\text { Compra e venda de imóveis (\%) }\end{array}$ & -0.003 & 0.089 & 0.038 & 0.120 & 0.004 & 0.873 \\
\hline
\end{tabular}

\footnotetext{
${ }^{3}$ Bancos, Caixas Económicas e Caixas de Crédito Agrícola Mútuo.
} 


\section{Factor 2 - Poder económico}

Os depósitos de clientes por habitante, em milhares de euros, constituem a variável dominante do factor 2 , o qual apresenta uma taxa de variância de $19 \%$. As variáveis que contribuem para o score deste factor encontram-se relacionadas com o poder económico da população residente em cada município. Considera-se que quanto maior for o poder económico, maior será a capacidade de implementar medidas de mitigação e de recuperação no caso da ocorrência de desastres ou catástrofes.

\section{Factor 3 - Parque habitacional}

O índice de envelhecimento dos edifícios é a variável que assume maior peso neste factor, que possui uma taxa de variância de $10 \%$. A época de construção dos edifícios, assim como as suas características estruturais são importantes. Considera-se que, quanto mais recente o edifício, maior será a sua qualidade e a resistência estrutural às perigosidades naturais, como acontecimentos climáticos extremos. Para além da variável relativa ao índice de envelhecimento dos edifícios, também integram o factor 3 as percentagens de edifícios construídos antes de 1919, de alojamentos com uma renda inferior a $100 €$ e de população empregada que se enquadra na CNP 1 (quadros superiores da administração pública, dirigentes e quadros superiores de empresa). No presente contexto considera-se que quanto mais envelhecido for o parque habitacional e menor a percentagem de população de determinado município empregada em actividades que se enquadram no CNP 1, mais elevado será o seu score correspondente ao factor 3.

\section{Factor 4 - Estrutura socioprofissional}

Este factor, com uma taxa de variância na ordem dos $7 \%$, incide sobre a estrutura da população empregada, constituindo a variável dominante a percentagem da população empregada que se enquadra na CNP 5 (pessoal dos serviços e vendedores). Esta variável apresenta uma relação inversa com a percentagem de população empregada que se enquadra na CNP 8 (operadores de instalações e máquinas e trabalhadores da montagem) e na CNP 7 (operários, artífices e trabalhadores similares). Na área em estudo observa-se uma relação inversa entre a população empregada no sector dos serviços e a população empregada no sector da indústria.

\section{Factor 5 - Beneficiários do Rendimento Social de Inserção}

O factor 5 explica 6\% da variância e é constituído apenas por uma variável - percentagem de beneficiários do Rendimento Social de Inserção. Constitui um indicador de carências económicas que contribuem para aumentar 
o nível de vulnerabilidade social. O nível de riqueza capacita as comunidades para absorverem e recuperarem rapidamente das perdas relacionadas com desastres ou catástrofes. Constitui um consenso geral que a capacidade económica dos indivíduos e das famílias é um dos factores essenciais na mitigação da vulnerabilidade social (Cutter et al., 2003).

\section{Factor 6 - Dinamismo económico}

O factor 6, com uma taxa de variância de 5\%, é constituído pela percentagem de actos notariais celebrados por escritura - compra e venda de imóveis. Trata-se de uma variável que reflecte o dinamismo económico dos municípios em estudo.

$\mathrm{Na}$ Figura 1 transparece a representação do índice de criticidade da vulnerabilidade social para Portugal continental. As cinco classes representam os valores de variação do desvio-padrão. ${ }^{4}$

A análise dos resultados da avaliação da criticidade à escala municipal permite verificar que os níveis de criticidade muito baixos se encontram concentrados, essencialmente, ao longo da faixa costeira, com particular evidência para as regiões norte e centro, assim como para a região do Algarve.

Os valores mais elevados de criticidade concentram-se no vale do rio Douro, nomeadamente nas subbacias do Tâmega, Sousa, Alto Vouga e Paiva, na zona fronteiriças do Alto e Baixo Alentejo e na área metropolitana de Lisboa. As regiões das Terras do Sado, Alentejo Central e Ribatejo apresentam genericamente valores médios de criticidade, denotando as regiões a norte do rio Douro os índices mais contrastados de criticidade. $\mathrm{Na}$ região centro observam-se, genericamente, valores das classes intermédias de criticidade.

Contudo, nesta última região é possível identificar, no Interior, municípios com baixos níveis de criticidade, como Castelo Branco, Fundão e Guarda. É importante assinalar que as razões pelas quais Lisboa, por exemplo, apresenta um nível de criticidade baixo são diferentes das razões pelas quais Viana do Castelo também apresenta um nível de criticidade baixo. $\mathrm{Na}$ capital, o resultado final da equação é determinado pelo poder económico da população, enquanto em Viana do Castelo o mesmo é muito influenciado pelas condições dos edifícios habitacionais.

Nos municípios a norte, os valores elevados e muito elevados no índice de criticidade são essencialmente determinados pelo fraco poder económico

\footnotetext{
${ }^{4}$ Muito Baixo: <-1D.P.; Baixo: entre -1 e -0.5D.P.; Médio: entre -0.5 e 0.5D.P.; Elevado: entre 0.5 e 1D.P.; Muito Elevado: > 1D.P.
} 
A vulnerabilidade social aos perigos naturais e tecnológicos em Portugal | 109

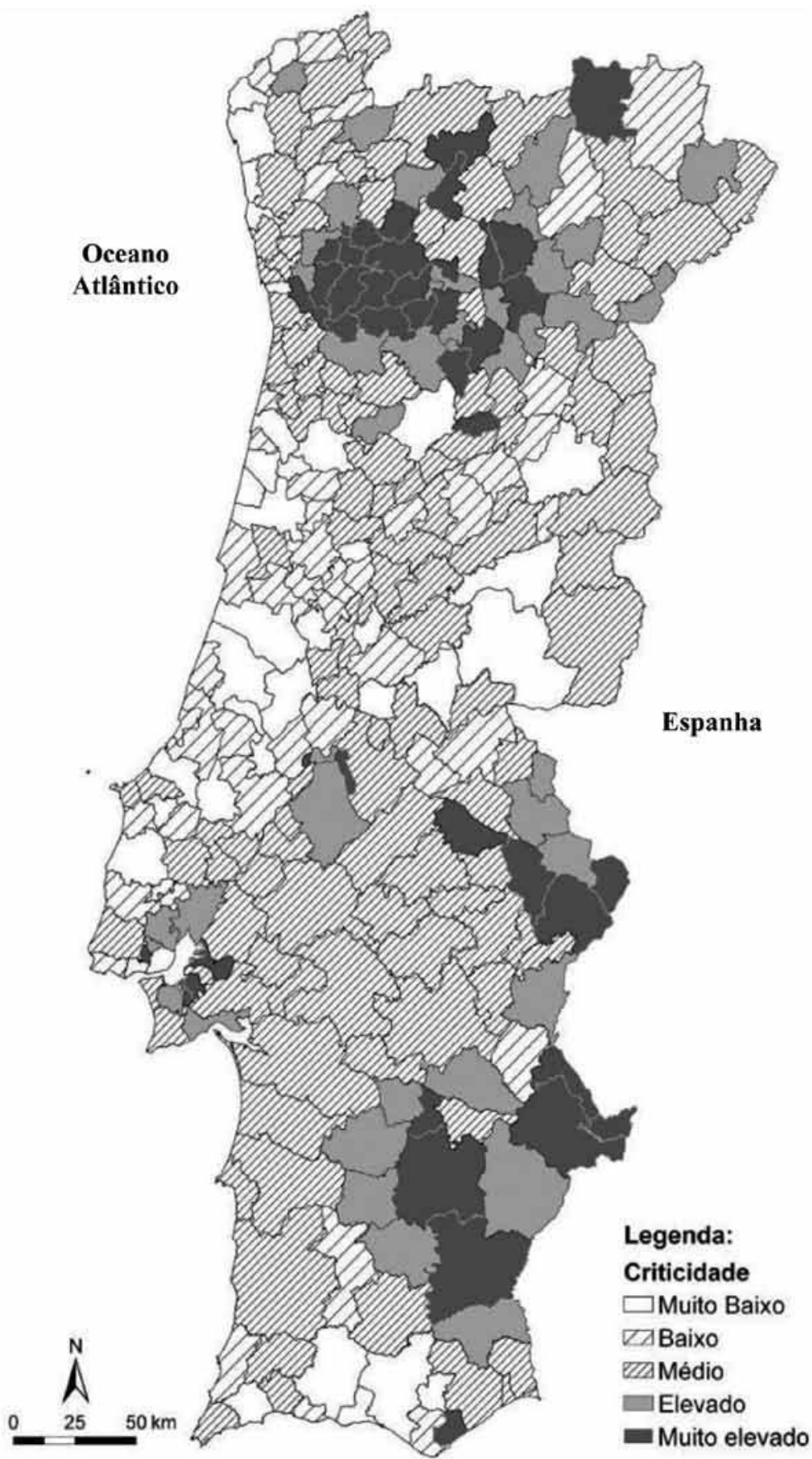

FIGURA 1 - Criticidade à escala municipal em Portugal 
da população, com particular ênfase para o factor 5 (percentagem de beneficiários do Rendimento Social de Inserção). Nos municípios localizados a sul os valores elevados e muito elevados de criticidade são determinados sobretudo pela influência dos factores 3 (condições dos edifícios) e 4 (estrutura profissional da população activa).

\subsection{A capacidade de suporte à escala municipal}

$\mathrm{Na}$ avaliação da capacidade de suporte à escala municipal foram retidos quatro factores: dinamismo económico e ambiental dos municípios (1); presença de corporações de bombeiros (2); capacidade logística e seguradora (3); farmácias por cada 10000 habitantes (4). A aplicação destes factores resulta dos dados constantes da Tabela 4.

Passamos, de seguida, a descrever com mais detalhe cada um dos factores. À semelhança do índice anterior, os resultados foram organizados em cinco classes que representam os valores de variação do desvio-padrão.

TABELA 4 - Matriz rodada de componentes - Capacidade de suporte

\begin{tabular}{|l|c|c|c|c|}
\hline \multicolumn{1}{|c|}{ Variáveis } & $\mathbf{1}$ & $\mathbf{2}$ & $\mathbf{3}$ & $\mathbf{4}$ \\
\hline Caixas multibanco (\%) & 0.868 & -0.034 & 0.082 & 0.016 \\
\hline Resíduos urbanos recolhidos - ton/100hab & 0.814 & -0.138 & -0.178 & 0.185 \\
\hline Bancos e caixas económicas (\%) & 0.708 & 0.238 & 0.316 & -0.162 \\
\hline Turismo - Taxa de ocupação - cama (bruta) & 0.567 & -0.467 & 0.201 & 0.052 \\
\hline Corporações de bombeiros (\%) & -0.054 & 0.889 & -0.059 & -0.035 \\
\hline Ambulâncias de transporte de doentes (Amb/ (\%) & 0.011 & 0.853 & -0.044 & 0.016 \\
\hline Proporção de camas (lotação praticada) por 1000 habitantes & 0.194 & -0.122 & 0.830 & -0.072 \\
\hline Proporção de hospitais por 10 000 habitantes & -0.216 & 0.042 & 0.599 & 0.457 \\
\hline Companhias de seguros (\%) & 0.464 & -0.396 & 0.494 & -0.150 \\
\hline Farmácias por 10 000 habitantes & 0.109 & -0.021 & -0.019 & 0.865 \\
\hline
\end{tabular}

\section{Factor 1: Dinamismo económico e ambiental}

Este factor, com uma taxa de variância de $31 \%$, tem como variável dominante a proporção de caixas multibanco por cada 1000 habitantes. Além destes indicadores, também integram este factor a proporção de bancos e caixas económicas por cada 1000 habitantes e a taxa de ocupação de camas das unidades hoteleiras. São variáveis que se apresentam como indicadores do dinamismo económico dos municípios em análise. 


\section{Factor 2: Corporações de bombeiros}

O factor 2, com uma taxa de variância de $17 \%$, tem como variável dominante o número de corporações de bombeiros por cada 1000 habitantes. Além disso, também integra a proporção de ambulâncias de doentes por cada 10000 habitantes, estando estas duas variáveis fortemente interrelacionadas. $O$ factor 2 representa, assim, um indicador de capacidade de suporte dos municípios no âmbito da protecção civil.

\section{Factor 3: Capacidade logística e seguradora}

Este factor apresenta uma taxa de variância de $12 \%$ e tem como variável dominante a lotação praticada de camas no sector hoteleiro por cada 1000 habitantes. Num cenário de desastre ou catástrofe, o número de camas existentes no sector hoteleiro constitui um recurso potencial de alojamento para desalojados e evacuados.

\section{Factor 4: Proporção de farmácias por 10000 babitantes}

O factor 4 apresenta uma taxa de variância explicativa na ordem dos $10 \%$ e é constituído apenas por uma variável: proporção de farmácias por cada 10000 habitantes. No contexto de avaliação da vulnerabilidade social, a dimensão da saúde das populações apresenta-se como um conjunto intrincado de condicionantes, tanto de âmbito individual como comunitário e estrutural (Phillips et al., 2009).

A projecção cartográfica dos resultados revela que os valores mais baixos em termos de capacidade de suporte evidenciam-se no norte do país, nomeadamente nas regiões das bacias dos rios Cávado, Ave, Tâmega e Vouga (Figura 2).

Os níveis mais elevados encontram-se essencialmente localizados no interior de Portugal, assim como na região do Algarve. O fraco dinamismo económico apresentado por alguns municípios do Norte e Centro desempenha um papel importante para que apresentem uma capacidade de suporte baixa. Contudo, alguns municípios apresentam uma capacidade de suporte baixa devido aos factores 3 (capacidade logística e actividade seguradora no território) e 4 (número de farmácias por 10000 habitantes). O dinamismo económico e ambiental (factor 1) e as farmácias (factor 4) desempenham um papel decisivo em municípios como Lisboa, Porto, Loulé e Santarém, que apresentam níveis de capacidade de suporte muito elevados. 


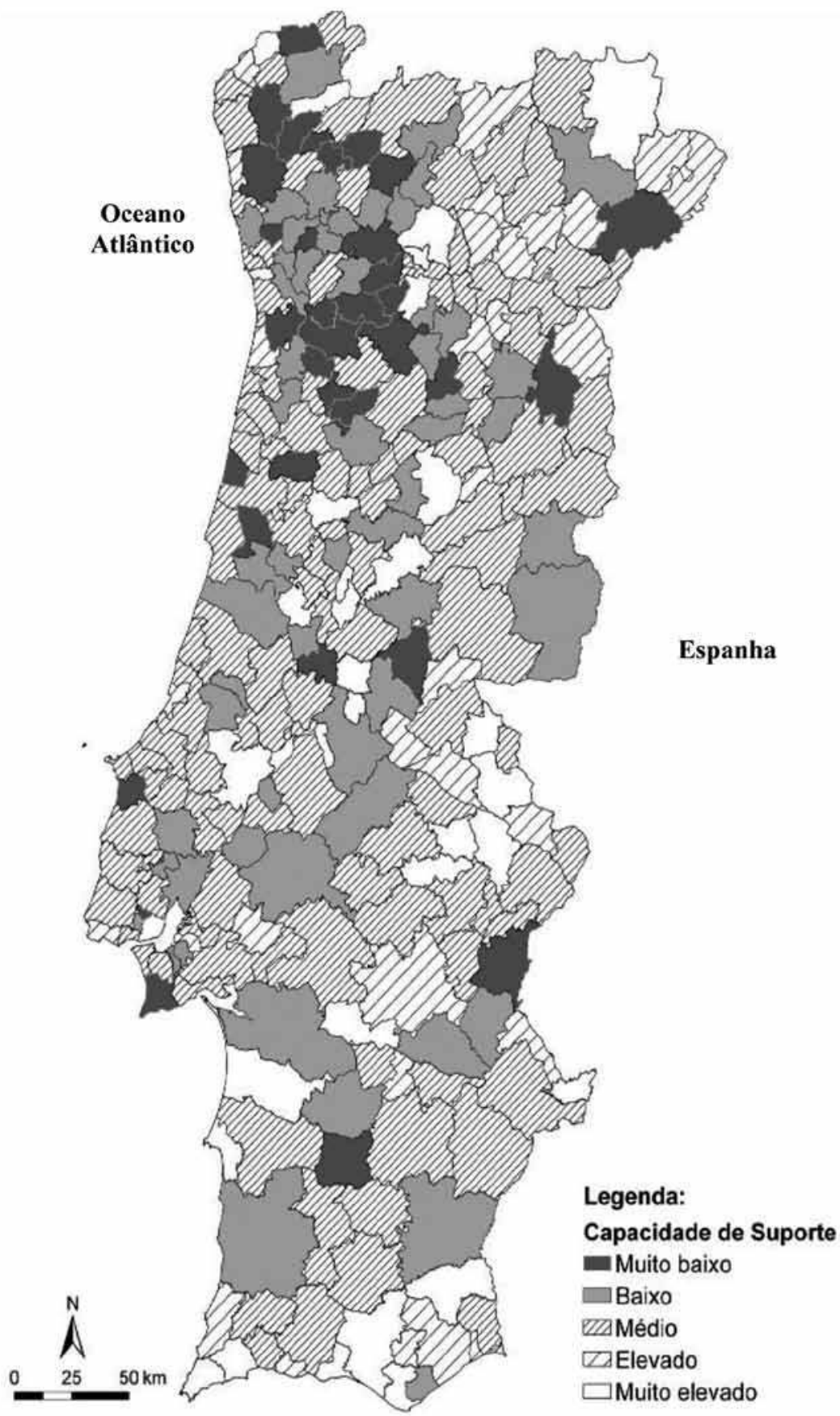

FIGURA 2 - Capacidade de suporte à escala municipal em Portugal 


\subsection{A vulnerabilidade social à escala municipal}

Apresentam-se seguidamente os resultados da vulnerabilidade social em Portugal continental, a partir do produto dos índices da criticidade e da capacidade de suporte ao nível municipal. É de salientar os valores muito elevados de vulnerabilidade social nos vales dos rios Lima, Cavado, Tâmega, Sousa, Vouga, Dão e Paiva, assim como os valores, genericamente, médios e baixos presentes em Trás-os-Montes, Beira Interior, Beira Litoral, Maciço Central, Oeste e Algarve (Figura 3).

Os municípios de Penacova, Constância, Fronteira, Seia, São João da Madeira, Lisboa, Barrancos, Porto, Loulé e Oeiras evidenciam-se como sendo os 10 municípios com o Índice de Vulnerabilidade Social (IVS) mais baixo de Portugal. Contudo, as razões que levam a que estes municípios apresentem estes valores são diferentes. No caso de Penacova, trata-se de um município que apresenta uma capacidade de suporte muito elevada devido aos factores 3 (capacidade logística e seguradora) e 4 (proporção de farmácias por cada 1000 habitantes). No entanto, o município de Penacova apresenta uma criticidade de nível médio, o que se deve a um valor abaixo da média no que se refere ao factor 2 (poder económico). O caso do município de Constância é ainda mais paradoxal que o de Penacova, na medida em que apresenta uma capacidade de suporte e um nível de criticidade muito elevados. O município de Lisboa, por seu turno, apresenta uma capacidade de suporte muito elevada e um nível de criticidade muito baixo, ou seja, as duas componentes da equação contribuem para que o Índice de Vulnerabilidade Social deste município seja globalmente baixo.

Em situação oposta aparecem os municípios de Resende, Castelo de Paiva, Cinfães, Baião, Celorico de Basto, Marco de Canavezes, Lousada, Paços de Ferreira, Olhão e Penalva do Castelo, que se destacam como sendo os 10 municípios de Portugal continental com os níveis mais elevados do Índice de Vulnerabilidade Social. $\mathrm{Na}$ análise dos dados do município de Resende verifica-se que o mesmo apresenta um valor de criticidade muito elevado e uma capacidade de suporte muito baixa. O valor de criticidade muito elevado deve-se em muito ao factor 5 (percentagem de beneficiários do Rendimento Social de Inserção), assim como a uma baixa capacidade de suporte baseada no factor 1 (dinamismo económico e ambiental).

Os resultados mostram que, na maioria dos casos, as capitais de distrito apresentam menores níveis de vulnerabilidade social que os municípios adjacentes, o que denota o padrão territorial de concentração de infraestruturas e de recursos económicos. 


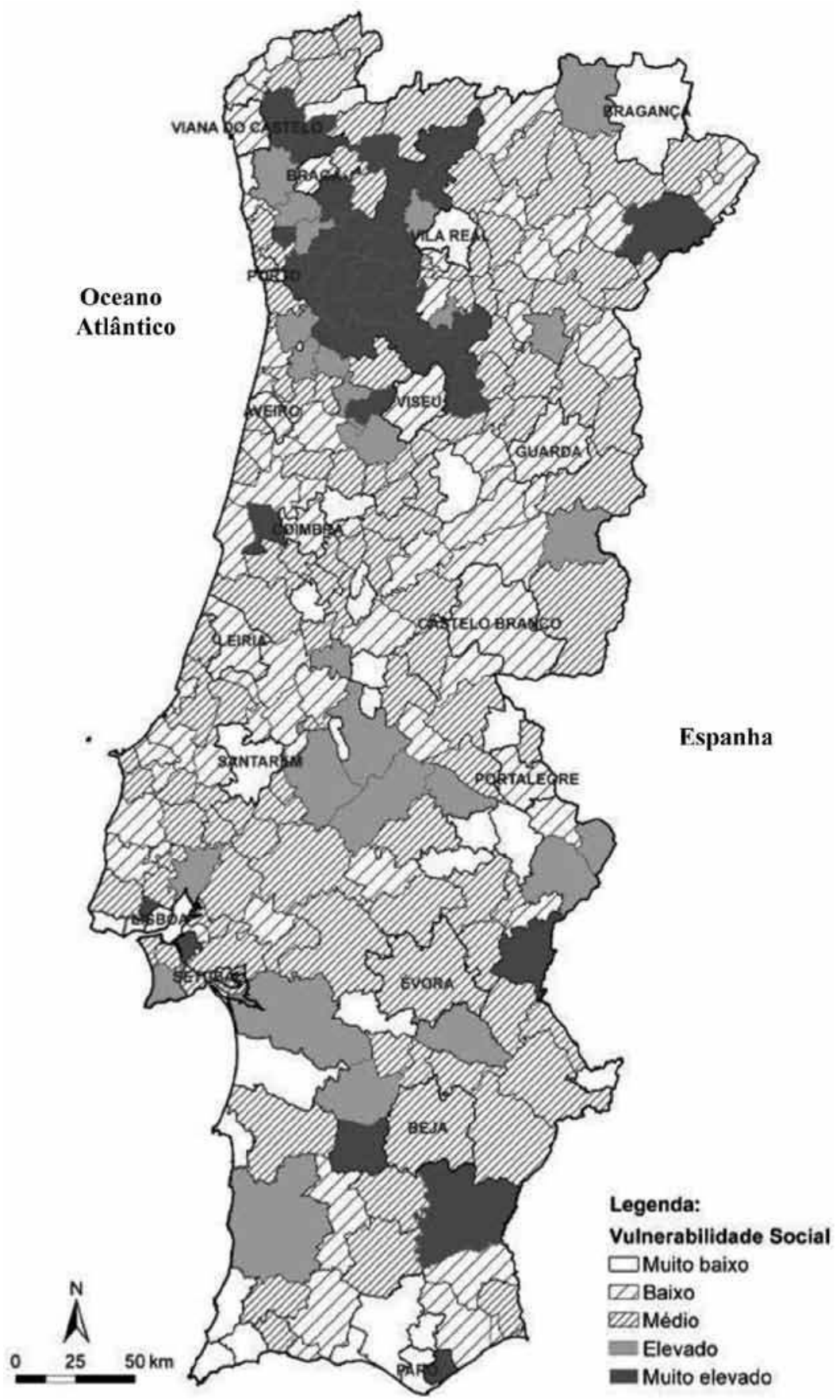

FIGURA 3 - Vulnerabilidade social à escala municipal em Portugal 
A mancha de municípios que se evidencia a norte de Portugal com um nível de vulnerabilidade social muito elevado deve-se, em muito, ao fraco poder económico da população residente e à fragilidade do seu tecido económico. Constitui algo semelhante ao que Kasperson et al. (1996) denominam bolsas de vulnerabilidade, definidas como áreas geográficas ou sectores da comunidade onde factores e processos convergem para destruir a capacidade de resposta a eventuais desastres ou catástrofes.

\section{O efeito da escala na análise da vulnerabilidade social}

A fim de testar as duas componentes da fórmula de avaliação da vulnerabilidade social (criticidade e capacidade de suporte) a uma escala submunicipal, bem como o impacto da variação de escala nos índices de vulnerabilidade social, foram seleccionados sete municípios da região centro de Portugal (Ovar, Coimbra, Marinha Grande, Nelas, Almeida e Proença-a-Nova). Este grupo de municípios apresenta uma grande heterogeneidade em termos biofísicos e socioeconómicos. Na elaboração da amostra foram tidos em conta nove parâmetros, no sentido de que a mesma fosse representativa dos 72 municípios da região centro de Portugal.

Os parâmetros considerados no processo de selecção tiveram em conta a localização (Litoral e Interior), a área geográfica do município, o número de habitantes, a densidade populacional, o número de freguesias, a área urbana e rural e a relevância das actividades industriais, agro-florestais e terciárias.

\subsection{A criticidade e capacidade de suporte ao nível submunicipal}

A avaliação da criticidade destes municípios, à escala da freguesia, foi feita com base em 79 variáveis. Com base na análise factorial, concluiu-se que 6 variáveis eram suficientes para explicar o modelo. A Tabela 5 sintetiza o número e a distribuição das variáveis incluídas no processo de avaliação.

Nesta avaliação foram retidos 3 factores, os quais explicam $78 \%$ da variância. O KMO da amostra é de 0.617 e todas as comunalidades apresentam um valor acima dos 0.6 . No primeiro factor, o qual explica $40 \%$ da variância, a variável dominante é a taxa de desemprego, seguida por variáveis relacionadas com a estrutura demográfica e agregando os grupos socialmente vulneráveis. O segundo factor, que explica $21 \%$ da variância, foca-se num grupo socialmente vulnerável, a população portadora de deficiência, com particular relevo para os indivíduos com um grau de incapacidade superior a $80 \%$. O terceiro factor, que explica $17 \%$ da variância, é constituído apenas pela percentagem de edifícios construídos antes de 1960, representando um factor útil na identificação das áreas urbanas mais consolidadas. 
TABELA 5 - Número de variáveis usadas na avaliação da criticidade à escala da freguesia

\begin{tabular}{|l|c|c|c|}
\hline \multirow{2}{*}{\multicolumn{2}{c|}{ Grupos }} & \multicolumn{3}{c|}{ Variáveis } \\
\cline { 2 - 4 } & Iniciais & Modelo & Explicativas \\
\hline Apoio social & 13 & 10 & 0 \\
\hline Demografia & 14 & 10 & 4 \\
\hline Economia & 30 & 21 & 1 \\
\hline Edifícios & 11 & 8 & 1 \\
\hline Habitação & 11 & 4 & 0 \\
\hline Total & 79 & 53 & 6 \\
\hline
\end{tabular}

$\mathrm{Na}$ avaliação da capacidade de suporte à escala da freguesia, foram recolhidas 100 variáveis, mas apenas 44 foram incluídas no modelo, tendo por base os mesmos sete municípios da região centro de Portugal. Na Tabela 6 encontra-se identificado o número de variáveis usadas nas várias fases de avaliação da capacidade de suporte nos sete municípios seleccionados para a amostra.

TABELA 6 - Número de variáveis na avaliação da capacidade de suporte das freguesias

\begin{tabular}{|l|c|c|c|}
\hline \multirow{2}{*}{\multicolumn{1}{|c|}{ Grupos }} & \multicolumn{3}{c|}{ Variáveis } \\
\cline { 2 - 4 } & Inicial & Modelo & Explicativas \\
\hline Economia & 59 & 15 & 2 \\
\hline Edifícios & 11 & 8 & 0 \\
\hline Equipamentos sociais & 5 & 3 & 2 \\
\hline Fornecimento de água & 10 & 10 & 3 \\
\hline Fornecimento de energia & 2 & 2 & 0 \\
\hline Habitação & 11 & 4 & 1 \\
\hline Saúde & 2 & 2 & 1 \\
\hline Total & 100 & 44 & 9 \\
\hline
\end{tabular}

$\mathrm{Na}$ avaliação da capacidade de suporte foram retidos 4 factores, que explicam $73 \%$ da variância e todas as comunalidades estão acima dos 0.5 . O primeiro factor, que explica $28.4 \%$ da variância, encontra-se relacionado com a qualidade do sistema de abastecimento de água das freguesias. O segundo factor explica $18.6 \%$ da variância e está relacionado com os equipamentos sociais, como os centros de dia e os jardins-de-infância, que são importantes na diminuição da vulnerabilidade aos perigos em 
determinados grupos etários (Mendes, 2009). O terceiro factor, que explica $14.5 \%$ da variância, encontra-se focado na CAE-D ${ }^{3}$, sobretudo quanto ao seu impacto na economia local. O quarto factor, que explica $11.6 \%$ da variância, resume-se à variável farmácias por 1000 pessoas.

$\mathrm{Na}$ Tabela 7 podemos observar os resultados da avaliação da criticidade para os sete municípios da amostra, em termos de indicadores estatísticos básicos.

TABELA 7 - Criticidade à escala da freguesia - Medidas de dispersão dos dados

\begin{tabular}{|l|c|c|c|c|}
\hline \multicolumn{1}{|c|}{ Município } & Média & Mínimo & Máximo & $\begin{array}{c}\text { Desvio- } \\
\text {-Padrão }\end{array}$ \\
\hline Almeida & 1.82 & -1.1 & 5.76 & 1.81 \\
\hline Coimbra & 0.89 & -1.48 & 5.32 & 1.79 \\
\hline Fundão & 0.02 & -2.3 & 2.33 & 1.02 \\
\hline Marinha Grande & 0.47 & 0.04 & 0.9 & 0.35 \\
\hline Nelas & 0.2 & -1.63 & 2.47 & 1.23 \\
\hline Ovar & 1.14 & 0.68 & 1.79 & 0.43 \\
\hline Proença-a-Nova & 0.2 & -0.36 & 0.98 & 0.43 \\
\hline Total & 0.8 & -2.3 & 5.76 & 1.6 \\
\hline
\end{tabular}

No que diz respeito aos elevados índices de criticidade decorrentes dos valores de desvio-padrão, evidenciam-se os municípios de Coimbra e Almeida. O terceiro factor (percentagem de edifícios construídos antes de 1960) desempenha um papel relevante em freguesias de urbanização mais antiga localizadas no centro da cidade de Coimbra, onde se observa uma elevada percentagem de população idosa. Este resultado confirma que o factor 3 é útil na identificação das áreas urbanas consolidadas.

Pelo contrário, os municípios de Marinha Grande e Proença-a-Nova apresentam valores de criticidade baixos e bastante homogéneos. A Marinha Grande é um município do Litoral onde o sector da indústria desempenha um papel importante, enquanto o município de Proença-a-Nova, no interior da região centro, apresenta um sector agro-florestal com relevo na economia local. Trata-se, assim, de dois municípios com características sociodemográficas e socioeconómicas distintas, o que significa que a criticidade não

\footnotetext{
${ }^{3}$ Encontram-se incluídas na CAE-D todas as actividades relacionadas com electricidade, gás, vapor, água quente e fria e ar frio.
} 
se encontra directamente relacionada com a urbanização ou as actividades económicas dominantes.

$\mathrm{Na}$ Tabela 8 é apresentado o número de freguesias no contexto municipal que apresentam valores de criticidade extremos. Este indicador evidencia, a nível municipal, a heterogeneidade das comunidades e dos indivíduos num cenário de desastre ou catástrofe. Os municípios de Almeida e de Coimbra apresentam um território heterogéneo, quando comparados com os resultados da Marinha Grande, Ovar e Proença-a-Nova. O município de Almeida possui o valor mais elevado em termos de criticidade, o que se deve a uma elevada percentagem relativa, quando comparada com os outros municípios, de indivíduos portadores de deficiência com um grau de incapacidade superior a $80 \%$. No que diz respeito ao número de freguesias com elevados níveis de criticidade, Almeida apresenta o maior valor, seguida por Coimbra.

TABELA 8 - Número de freguesias com os níveis mais baixos e elevados de criticidade

\begin{tabular}{|l|c|c|c|}
\hline Município & Número de freguesias & $\begin{array}{c}\text { Freguesias com o nivel } \\
\text { mais baixo }\end{array}$ & $\begin{array}{c}\text { Freguesias com o nível } \\
\text { mais elevado }\end{array}$ \\
\hline Almeida & 29 & 1 & 11 \\
\hline Coimbra & 31 & 3 & 7 \\
\hline Fundão & 31 & 5 & 0 \\
\hline Marinha Grande & 3 & 0 & 0 \\
\hline Nelas & 9 & 2 & 0 \\
\hline Ovar & 8 & 0 & 0 \\
\hline Proença-a-Nova & 6 & 0 & 19 \\
\hline Total & 117 & 11 & \\
\hline
\end{tabular}

No município de Almeida, onze das freguesias apresentam o nível de criticidade mais elevado, o que o torna um dos municípios a necessitar de estratégias específicas de mitigação e informação/sensibilização para o risco na região.

$\mathrm{Na}$ Tabela 9 aparecem representados os resultados decorrentes da avaliação da capacidade de suporte à escala da freguesia, em termos de medidas de dispersão. O valor mais elevado é registado em Nelas, devido à produção industrial e às actividades económicas presentes neste município. $\mathrm{Na}$ mesma tabela, o município de Coimbra distingue-se pela freguesia com o valor mais baixo em termos de capacidade de suporte, correspondendo este facto ao factor 1 (sistema de abastecimento de água). 
TABELA 9 - Capacidade de suporte à escala da freguesia - Medidas de dispersão

\begin{tabular}{|l|c|c|c|c|}
\hline \multicolumn{1}{|c|}{ Municípios } & Média & Mínimo & Máximo & Desvio-Padrão \\
\hline Almeida & 0.6 & -1.39 & 5.88 & 1.63 \\
\hline Coimbra & -0.45 & -2.40 & 7.83 & 2.47 \\
\hline Fundão & -0.43 & -1.77 & 1.47 & 0.85 \\
\hline Marinha Grande & 1.8 & -0.46 & 2.94 & 1.59 \\
\hline Nelas & 0.72 & -1.91 & 9.24 & 3.41 \\
\hline Ovar & 0.2 & -1.03 & 2.92 & 1.23 \\
\hline Proença-a-Nova & -0.67 & -1.88 & 1.6 & 1.22 \\
\hline Total & 0 & -2.4 & 9.24 & 1.99 \\
\hline
\end{tabular}

Pelos dados constantes da Tabela 10 verifica-se que Coimbra apresenta um grande contraste territorial em termos de capacidade de suporte, o que não acontece nos municípios do Fundão e Proença-a-Nova. Os resultados de Almeida evidenciam uma elevada capacidade de suporte em cinco freguesias deste município, consequência do elevado valor apresentado no factor 1 .

TABELA 10 - Número de freguesias com os níveis mais baixos e mais elevados de capacidade de suporte

\begin{tabular}{|l|c|c|c|}
\hline \multicolumn{1}{|c|}{ Municípios } & Número de freguesias & $\begin{array}{c}\text { Freguesias com o nível } \\
\text { mais baixo }\end{array}$ & $\begin{array}{c}\text { Freguesias com o nível } \\
\text { mais elevado }\end{array}$ \\
\hline Almeida & 29 & 0 & 5 \\
\hline Coimbra & 31 & 6 & 4 \\
\hline Fundão & 31 & 0 & 0 \\
\hline Marinha Grande & 3 & 0 & 2 \\
\hline Nelas & 9 & 0 & 2 \\
\hline Ovar & 8 & 0 & 1 \\
\hline Proença-a-Nova & 6 & 0 & 0 \\
\hline Total & 117 & 6 & 14 \\
\hline
\end{tabular}

Constata-se ser maior o número de freguesias com um nível elevado de capacidade de suporte do que o número de freguesias com um nível de capacidade de suporte muito baixo. Tal pode ser considerado um indicador de uma elevada capacidade de resistência das comunidades locais ao impacto de desastres e catástrofes de origem natural ou tecnológica. É de assinalar o papel desempenhado pelas Câmaras Municipais, nomeadamente na época posterior à Revolução do 25 de Abril e da integração de Portugal na 
União Europeia em 1986, com aplicação dos fundos estruturais no melhoramento das infraestruturas e das condições de vida das populações locais. As diferenças verificadas na avaliação da capacidade de suporte evidenciam a heterogeneidade da estrutura territorial da região centro, atenuada pelas políticas municipais de aplicação de fundos estruturais, na captação de investimentos privados e no desenvolvimento de infraestruturas de apoio com reflexo na resiliência das comunidades.

\subsection{A vulnerabilidade social à escala submunicipal e a relevância da escala} A vulnerabilidade social foi analisada em duas escalas: uma avaliação desagregada ao nível do município no quadro de Portugal continental e uma avaliação ao nível submunicipal levada a cabo num contexto regional, com base numa amostra de sete municípios da região centro de Portugal. $\mathrm{Na}$ análise da Tabela 11 verifica-se a existência de valores bastante contrastados, em ambos os níveis de análise, sendo importante ter em atenção que os valores elevados de criticidade contribuem para aumentar a vulnerabilidade social e os valores elevados relativos à capacidade de suporte contribuem para diminuir os níveis de vulnerabilidade social.

TABELA 11 - Índice de Vulnerabilidade Social - A relevância das escalas

\begin{tabular}{|c|c|c|c|c|c|}
\hline \multicolumn{3}{|c|}{ Município } & \multicolumn{3}{c|}{ Freguesia } \\
\hline Nome & Criticidade & $\begin{array}{c}\text { Capacidade } \\
\text { de suporte }\end{array}$ & Nome & Criticidade & $\begin{array}{c}\text { Capacidade } \\
\text { de suporte }\end{array}$ \\
\hline Penacova & 1.17 & 9.89 & Fundão & -2.29 & 0.79 \\
\hline Fundão & -0.89 & 0.95 & Fatela & -0.49 & -0.9 \\
\hline Alcoutim & 2.91 & 2.74 & Bogas de Baixo & 2.33 & 0.38 \\
\hline Vila Viçosa & 0.61 & 0.86 & Vil de Matos & -0.39 & -0.34 \\
\hline Coimbra & 0.13 & 0.26 & Cernache & 0.11 & 2.73 \\
\hline Almeirim & 0.72 & -0.141 & Almedina & 5.32 & 0.37 \\
\hline Góis & 1.60 & 0.53 & Nelas & 0.86 & 9.24 \\
\hline Nelas & 1.21 & -0.35 & Santar & -0.24 & 0.74 \\
\hline Resende & 7.22 & -2.67 & Lapa do Lobo & 2.47 & -0.59 \\
\hline
\end{tabular}

No que diz respeito à criticidade, Almedina, no município de Coimbra, é a freguesia que apresenta o valor mais elevado, devendo-se tal facto, essencialmente, à elevada percentagem de indivíduos residentes com mais de 65 anos. Embora esta seja uma das freguesias que compõem o centro histórico 
de Coimbra, não apresenta uma capacidade de suporte elevada. No Município de Nelas, a freguesia sede de concelho apresenta uma capacidade de suporte muito elevada, o que faz ressaltar a importância das políticas locais e regionais de investimento, criação de infraestruturas e apoio social, salientando os contrastes intermunicipais e submunicipais.

A nível nacional, as diferenças entre os resultados são bastante relevantes, contrastando Penacova, com um valor de criticidade de 1.17, com o município de Resende, com um valor de 7.22, sobretudo devido ao elevado peso dos beneficiários do Rendimento Social de Inserção. O município de Alcoutim constitui um caso interessante, dado possuir elevados níveis de criticidade e simultaneamente uma capacidade de suporte elevada. Este município, embora com uma estrutura etária envelhecida, encontra-se bem servido em termos de estruturas de protecção civil, o que contribui para diminuir os níveis globais de vulnerabilidade social.

As duas componentes da equação de avaliação da vulnerabilidade social (criticidade e capacidade de suporte) não apresentam uma correlação linear, sendo tal facto visível tanto ao nível do município como ao nível submunicipal da freguesia. Além disso, os municípios, quando desagregados ao nível da freguesia, evidenciam uma elevada heterogeneidade, podendo-se apontar, como exemplo, o Município de Coimbra, onde a freguesia de Vil de Matos tem um índice de criticidade de -0.39 e a freguesia de Almedina um índice de 5.32. Estes resultados vêm confirmar a importância de uma avaliação da vulnerabilidade social desagregada ao nível submunicipal, nomeadamente da freguesia, na definição das políticas públicas de prevenção e de mitigação do risco.

Segundo Schmidtlein et al. (2008), enquanto as mudanças de escala afectam a análise factorial de componentes principais e as propriedades matemáticas do índice, a identificação dos factores de vulnerabilidade numa determinada área de estudo, havendo um conjunto de variáveis constante, que não depende muito da escala de agregação utilizada para definir a área de estudo.

No presente trabalho, em contradição parcial com os resultados obtidos por Schmidtlein et al. (2008), o modelo desenvolvido aponta para o facto de que cada escala aplicada (municipal e submunicipal) requer diferentes variáveis de consolidação do modelo, emergindo a cada nível escalar factores distintos de agregação dos dados. Os resultados fazem ainda sobressair que não se identifica uma relação linear entre a desagregação da unidade geográfica, o número de factores e a taxa de variância (Tabela 12), facto que corrobora a importância da avaliação da vulnerabilidade social a diferentes escalas. 
TABELA 12 - A influência da escala na análise factorial

\begin{tabular}{|l|c|c|c|c|c|c|}
\hline \multirow{2}{*}{ Parâmetros estatísticos } & \multicolumn{2}{|c|}{ Município } & \multicolumn{2}{c|}{ Freguesia } & \multicolumn{2}{c|}{ Secção estatística } \\
\cline { 2 - 7 } & $\begin{array}{c}\text { Critici- } \\
\text { dade }\end{array}$ & $\begin{array}{c}\text { Capacidade } \\
\text { de suporte }\end{array}$ & $\begin{array}{c}\text { Critici- } \\
\text { dade }\end{array}$ & $\begin{array}{c}\text { Capacidade } \\
\text { de suporte }\end{array}$ & $\begin{array}{c}\text { Critici- } \\
\text { dade }\end{array}$ & $\begin{array}{c}\text { Capacidade } \\
\text { de suporte }\end{array}$ \\
\hline N. ${ }^{\circ}$ de factores & 6 & 4 & 7 & 7 & 3 & 4 \\
\hline Taxa de variância (\%) & 76 & 71 & 75 & 64 & 71 & 73 \\
\hline
\end{tabular}

O modelo proposto faz ainda salientar municípios com diferentes estratégias públicas, o que resulta numa representação cartográfica policêntrica, dado que a cartografia da vulnerabilidade social estabelece uma análise comparativa entre as áreas territoriais, tanto na criticidade como na capacidade de suporte, contribuindo para uma melhor gestão de recursos e infraestruturas e definição de estratégias em termos de políticas públicas de prevenção e mitigação do risco.

\section{Conclusão}

Neste artigo apresenta-se um novo modelo de análise da vulnerabilidade social aos perigos naturais e tecnológicos. O índice utilizado nesta análise permite a estruturação da avaliação da vulnerabilidade em duas dimensões: as vulnerabilidades das populações e comunidades (criticidade) e a vulnerabilidade territorial (capacidade de suporte), os quais reflectem a exposição ou a vulnerabilidade biofísica, a resiliência social e a capacidade de suporte infraestrutural. Esta nova medida da vulnerabilidade social está de acordo com a proposta de Schmitlein et al. (2008), que avança com a necessidade de se integrar a investigação em ciências sociais sobre a vulnerabilidade social na gestão do risco, da emergência e do socorro. Argumentámos neste artigo que esta integração tem que atender ao papel da escala e à dinâmica territorial nos diferentes níveis de análise.

A vulnerabilidade social foi avaliada em duas escalas de análise, procurando-se salientar a capacidade do modelo e expressar as variações territoriais dos factores explicativos.

$\mathrm{Na}$ análise da criticidade os factores mais relevantes à escala municipal são a estrutura demográfica e o poder económico dos municípios. Ao nível da freguesia já os factores mais importantes para a criticidade são a presença de grupos socialmente vulneráveis e o peso morfológico das pessoas portadoras de deficiência. $\mathrm{Na}$ análise da capacidade de suporte, enquanto à escala municipal os factores mais significativos são o dinamismo económico e ambiental e a presença no território de corpos de bombeiros, à escala da 
freguesia salientam-se a qualidade do sistema de abastecimento de água e a existência de equipamentos sociais.

Em ambas as dimensões da vulnerabilidade social estudadas conclú́mos que os factores relevantes a nível municipal assumem um carácter mais estrutural, que exige uma abordagem estratégica de planeamento. A mitigação e a prevenção da vulnerabilidade social ao nível das freguesias exigem medidas mais orientadas e de cariz específico.

O lugar e a escala são fundamentais na análise da vulnerabilidade social, o que significa que um modelo que funciona bem num lugar, provavelmente não funcionará bem noutro contexto geográfico. Cada lugar possui características territoriais socioeconómicas, políticas e culturais próprias. Como foi demonstrado neste trabalho, os factores que influenciam o resultado final da equação da vulnerabilidade social diferem de lugar para lugar, de acordo com o enquadramento de referência usado na análise (nacional ou regional). Todavia, o modelo global revela-se consistente em diferentes escalas, permitindo a definição de estratégias de mitigação do risco e medidas de protecção civil específicas e adaptadas aos lugares em estudo.

A cartografia da vulnerabilidade social permite a comparação entre lugares, tanto no que diz respeito à criticidade como em relação à capacidade de suporte, constituindo um contributo para uma melhor gestão dos recursos e dos meios, assim como uma orientação para as políticas públicas de prevenção, redução, mitigação e sensibilização ao risco. Considera-se também importante assinalar que as variáveis usadas à escala municipal mostram uma realidade diferente das usadas à escala da freguesia. Os objectivos que regem uma análise municipal são diferentes daqueles que orientam uma análise à escala da freguesia, pelo que se realça que a caracterização estabelecida deve enformar distintas estratégias de intervenção, dependentes da escala.

Uma boa avaliação da vulnerabilidade social, atenta ao efeito de escala e ao papel crucial das desigualdades sociais e das assimetrias territoriais, que integre tanto a criticidade como a capacidade de suporte, possibilitará uma melhor definição de estratégias de prevenção, de resposta e de mitigação dos riscos naturais e tecnológicos em Portugal. 


\section{Referências bibliográficas}

Adger, Neil; Brooks, Nick; Bentham, Graham; Agnew, Maureen; Eriksen, Siri (2004), New Indicators of Vulnerability and Adaptive Capacity. Norwich: Tyndall Centre for Climate Change Research - Technical Report 7.

ANPC - Autoridade Nacional da Proteç̧ão Civil (2009), Guia para a caracterização de risco no âmbito da elaboração de planos de emergência de proteç̧ão civil. Lisboa: Autoridade Nacional da Protecção Civil.

Bankoff, Greg (2004), "The Historical Geography of Disaster: Vulnerability and local knowledge”, in Greg Bankoff, Georg Frerks e Dorothea Hilhorst (orgs.), Mapping Vulnerability: Disasters, development and people. London: Earthscan, 25-36.

Belmonte, Ana; López-García, María; García, Julián (2008), "Cartografía de vulnerabilidad frente a inundaciones en llanos mediterráneos. Caso de estudio del Barrranc de Carraixet e Rambla de Poyo", Serie Geográfica - Profesora María de los Ángeles Díaz Muñoz, In Memoriam, 14, 75-91.

Birkmann, Jörn (2006), Measuring Vulnerability to Natural Hazards. New Delhi: United Nations University.

Bohle, Hans; Downing, Thomas; Watts, Michael (1994), "Climate Change and Social Vulnerability: Toward a sociology and geography of food insecurity", Global Environmental Change, 4(1), 37-48.

Bolin, Bob (2006) "Race, Class, Ethnicity, and Disaster Vulnerability", in Havidán Rodriguez, Enrico Quarantelli e Russel Dynes (orgs.), Handbook of Disaster Research. New York: Springer, 113-129.

Cox, Louis (2009) "Improving Risk-Based Decision Making for Terrorism Applications", Risk Analysis, 29(3), 336-341.

Cutter, Susan (2003) "The Vulnerability of Science and the Science of Vulnerability", Annals of the Association of American Geographers, 93(1), 1-12.

Cutter, Susan (2006), "Moral Hazard, Social Catastrophe: The changing face of vulnerability along the hurricane coasts", The Annals of the American Academy of Political and Social Science, 604(1), 102-112.

Cutter, Susan (2010), "The Social Sciences Perspectives on Hazards and Vulnerability Science", Geophysical Hazards, 1, 17-30.

Cutter, Susan; Boruff, Bryan; Sherley, W. Lynn (2003), "Social Vulnerability to Environmental Hazards”, Social Science Quarterly, 84(2), 242-261.

Cutter, Susan; Emrich, Christopher; Mitchell, Jerry; Boruff, Bryan; Schimidtlein, Mathew; Burton, Christopher; Melton, Ginni (2006) "The Long Road Home: Race, class, and recovery from hurricane Katrina", Environment: Science and Policy for Sustainable Development, 48(2) 8-20.

Cutter, Susan; Barnes, Lindsey; Berry, Melissa; Burton, Christopher; Evans, Elijah; Tate, Eric; Webb, Jennifer (2008), "A Place-Based Model for Understanding Community Resilience to Natural Disasters”, Global Environmental Change, 18(4), 598-606. 
Davis, Ian (2004), "Progress in the Analysis of Vulnerability and Capacity", in Havidán Rodriguez, Enrico Quarantelli e Russel Dynes (orgs.), Handbook of Disaster Research. New York: Springer, 128-144.

de Graaf, Rutger; van de Giesen, Nick; van de Ven, Frans (2009), “Alternative Water Management Options to Reduce Vulnerability for Climate Change in the Netherlands", Natural Hazards, 51(3), 407-422.

Dwyer, Anita; Zoppou, Christopher; Nielson, Ole; Day, Susan; Roberts, Stephen (2004), Quantifying Social Vulnerability: A methodology for identifying those at risk to natural hazards. Australia: Geoscience Australia Record.

Eakin, Hallie; Luers, Amy (2006), “Assessing the Vulnerability of Social-Environmental Sytems", Annual Review of Environment and Resources, 31, 365-394.

EC-DGE - European Commission, DG Environment (2008), Assessing the Potential for a Comprehensive Community Strategy for the Prevention of Natural and Manmade Disasters. Final Report. Brussels: European Commission DG Environment, COWI.

Fekete, Alexander (2009), "Validation of a Social Vulnerability Index in Context to River-Floods in Germany", Natural Hazards and Earth System Sciences, 9, 393-403.

Fraser, Evan; Mabbe, Warren; Slaymaker, Olav (2003), "Mutual Vulnerability, Mutual Dependence: The reflexive relation between human society and the environment", Global Environmental Change, 13, 137-144.

Füssel, Hans-Martin (2007), "Vulnerability: A generally applicable conceptual framework for climate change research", Global Environmental Change, 17, 155-167.

Glatron, Sandrine; Beck, Elise (2008), "Evaluation of Socio-Spatial Vulnerability of Citydwellers and Analysis of Risk Perception: Industrial and seismic risks in Mulhouse", Natural Hazards and Earth System Sciences, 8, 1029-1040.

Guha-Sapir, Debby; Vos, Femke; Below, Regina; Ponserre, Sylvain (2011), Annual Disaster Statistical Review 2010: The Numbers and Trends. Brussels: Centre for Research on the Epidemiology of Disasters.

Hewitt, Kenneth (1983), Interpretations of Calamity from the Viewpoint of Human Ecology. London: Allen and Unwin.

Hufschmidt, Gabi (2011), “A Comparative Analysis of Several Vulnerability Concepts”, Natural Hazards, 58(2), 621-643.

Hufschmidt, G., Crozier, M., Glade, T. (2005), "Evolution of Natural Risk: Research framework and perspectives", Natural Hazards and Earth System Sciences, 5, 375-387. Iglesias, Ana; Moneo, Marta; Quiroga, Sonia (2009), "Methods for Evaluating Social Vulnerability to Drought", in Ana Iglesias, Luis Garrote, Antonino Cancelliere, Francisco Cubillo e Donald A. Dilhite (orgs.), Coping with Drought Risk in Agriculture and Water Supply Systems. Springer, 153-159.

ISDR - International Strategy for Disaster Reduction (2004), Living with Risk. A Global Review of Disaster Reduction Initiatives. Geneva, Switzerland: United Nations. 
Consultado a 15/01/2011, em http://www.unisdr.org/eng/about_isdr/bd-lwr-2004-eng.htm.

ISDR - International Strategy for Disaster Reduction (2005), Hyogo framework for 2005-2015: Building the resilience of nations and communities to disasters. Geneva, Switzerland: United Nations. Consultado a 15/01/2011, em http://www.unisdr. org/wcdr/intergover/official-doc/L-docs/Hyogo-framework-for-action-english.pdf. ISDR - International Strategy for Disaster Reduction (2011), 2011 Global Assessment Report on Disaster Risk Reduction: Revealing risk, redefining development. Geneva, Switzerland: United Nations. Consultado a 15/01/2011, em http://www.preventionweb.net/english/hyogo/gar/2011/en/home/index.html.

IFRCRCS - International Federation of Red Cross and Red Crescent Societies (2010), World Disaster Report 2010. Focus on Urban Risk. Geneva: IFRCRCS.

Kasperson, Roger E.; Kasperson, Jeanne X. (1996), "The Social Amplification of Risk", The Annals of the American Academy of Political and Social Science, 545(1), 95-105.

Keskitalo, Carina (2008), "Vulnerability and Adaptive Capacity in Forestry in Northern Europe: A Swedish case study”, Climatic Change, 87, 219-234.

Kropp, Jürgen; Block, A.; Reusswing, F.; Zickfeld, Kirsten; Schellnhauber, Hans (2006), "Semiquantitative Assessment of Regional Climate Vulnerability: The North-Rhine Westphalia study", Climatic Change, 76, 265-290.

Kuhlicke, Christian; Scolobig, Anna; Tapsell, Sue; Steinführer, Annett; de Marchi, Bruna (2011), "Contextualizing Social Vulnerability: Findings from case studies across Europe", Natural Hazards, 58(2), 789-810.

Kumpulainen, Satu (2006), "Vulnerability Concepts in Hazard and Risk Assessment", in P. Schmidt-Thome (org.), Natural and Technological Hazards and Risks Affecting the Spatial Development of European Regions. Geological Survey of Finland, Special Paper, 42, 65-74.

Langridge, Ruth; Christian-Smith, Juliet; Lhose, Kathleen (2006), "Access and Resilience: Analyzing the Construction of Social Resilience to the Threat of Water Scarcity", Ecology and Society, 11(2), 18. Consultado a 15/01/2011, em http://www. ecologyandsociety.org/vol11/iss2/art18/.

Manyena, Siambabala Bernard (2006), "The Concept of Resilience Revisited”, Disasters, 30(4), 434-450.

Maskry, Andrew (1989), Disaster Mitigation. A Community Based Approach. Oxford: Oxfam.

Mendes, José Manuel (2007), "Vulnerabilidade social, risco e segurança das populações: o papel do planeamento”, in Carlos Guedes Soares, A. P. Teixeira e P. Antão (orgs.), Riscos públicos e industriais, Vol. I. Lisboa: Edições Salamandra, 33-44.

Mendes, José Manuel (2009), "Social Vulnerability Indexes as Planning Tools: Beyond the preparedness paradigm”, Journal of Risk Research, 12(1), 43-58. 
Mendes, José Manuel; Tavares, Alexandre (2009), "Building Resilience to Natural Hazards. Practices and Policies on Governance and Mitigation in the Central Region of Portugal”, in Sebastian Martorell, C. Guedes Soares e Julie Barnett (orgs.), Safety, Reliability and Risk Analysis. Vol. 2, Theory, Methods and Applications. Leiden: CRC Press/Taylor \& Francis Group, 1577-1584.

Mendes, José Manuel; Tavares, Alexandre; Cunha, Lúcio; Freiria, Susana (2010), "Social Vulnerability to Natural and Technological Hazards: The relevance of scale", in R. Briš, C. Guedes Soares e S. Martorell (orgs.), Reliability, Risk and Safety. Vol. 1, Theory and Applications. Leiden: CRC Press/Taylor \& Francis Group, 445-451.

Mitchell, Tom; Haynes, Katherine; Choong, Wei; Hall, Nick; Oven, Katie (2008), “The Role of Children and Youth in Communicating Disaster Risk", Children, Youth and Environments, 18(1), 254-279.

Oliver-Smith, Anthony (2004), "Theorizing Vulnerability in a Globalized World: A Political Ecological Perspective”, in Greg Bankoff, Georg Frerks e Dorothea Hilhorst (orgs.), Mapping Vulnerability: Disasters, development and people. London: Earthscan, 10-24.

Peduzzi, Pascal; Dao, Hy; Herold, Christian; Mouton, Frederic (2009), “Assessing Global Exposure and Vulnerability towards Natural Hazards: The Disaster Risk Index", Natural Hazards and Earth System Sciences, 9, 1149-1159.

Perrow, Charles (2006), "Disasters Ever More? Reducing U.S. Vulnerabilities”, in Havidán Rodriguez, Enrico Quarantelli e Russel Dynes (orgs.), Handbook of Disaster Research. New York: Springer, 521-533.

Perrow, Charles (2007), The Next Catastrophe. Reducing our Vulnerabilities to Natural, Industrial, and Terrorist Disasters. Princeton: Princeton University Press.

Phillips, Brenda; Thomas, Deborah; Fothergill, Alice; Pike-Blinn, Lynn (2009), Social Vulnerability to Disasters. Boca Raton, Florida: CRC Press - Taylor and Francis Group.

Prescott-Allen, Robert (2001), The Wellbeing of Nations: A country-by-country index of quality of life and the environment. Washington: Island Press.

Ribeiro, Manuel João (1995), “Sociologia dos desastres”, Sociologia, Problemas e Práticas, $18,23-43$.

Ribeiro, Manuel João (2006), "A construção de um modelo de análise da vulnerabilidade social aos desastres. Uma aplicação à colina do Castelo de S. Jorge”, Territorium, $13,5-24$.

Roselló, Maria José; Martinez, José Maria; Navarro, Bartolome (2009), "Vulnerability of Human Environment to Risk: Case of groundwater contamination risk", Environment International, 35, 325-335.

Schmidtlein, Mathew; Deutsch, Roland; Piegorsch, Walter; Cutter, Susan (2008), "A Sensitivity Analysis of the Social Vulnerability Index", Risk Analysis, 28(4) 1099-1114. 
Tapsell, Sue; McCarthy, Simon; Faulkner, Hazel; Alexander, Meghan (2010), Social Vulnerability to Natural Hazards. London: CapHaz-Net Consortium, Flood Hazard Research Centre, Middlesex University. Consultado a 15/01/2011, em http:// caphaz-net.org/outcomes-results/CapHaz-Net_WP4_Social-Vulnerability2.pdf.

Tavares, Alexandre; Mendes, José Manuel; Freiria, Susana (2010), "Cartografia dei rischi naturali e della vulnerabilità sociale: la rilevanza della scala e delle politiche pubbliche di sviluppo", in Emanuela Casti e Jacques Lévy (orgs.), Le sfide cartografiche - Movimento, partecipazione e rischio. Bergamo: Il Lavoro Editoriale Università, 299-312.

Wisner, Ben, Blaikie, Piers, Cannon, Terry, and Davis, Ian (2004) At Risk - Natural bazards, people's vulnerability and disasters. Londres: Routledge.

WEF - World Economic Forum (2010), Global Risks 2010. A Global Risk Network Report. Cologny/Geneva, Switzerland: World Economic Forum. 